\title{
Time Wasters Related to Decision-making in Private Companies: An Empirical Study on Saudi Telecom Company (STC).
}

\author{
Amir Salim Elsheikh Algarrai, Adil Salim Elsheikh \\ Community College - University of Najran, Saudi Arabia
}

\begin{abstract}
This study aimed to identify time wasters related to decision-making in the Saudi Telecom Company (STC) as a model for the rest of the private companies in Saudi Arabia. In this study deductive approach, analytical and descriptive methods were used (questionnaire, interview, observation). A questionnaire was distributed to the sample of the study ( $n=75$ individuals). Fifty completed questionnaire were recovered which represent a response rate of $67 \%$. The data were uploaded into tables especially prepared for this purpose, where the nominal variables (strongly agree, agree, agree to a certain extent, I do not agree, do not agree at all) were converted into numerical variable $(5,4,3,2,1)$, respectively. The study revealed that high percent ( $p<0.02)$ of the respondent resort to committees to make decisions in STC. Furthermore, the percent of those who suffer hesitancy in decision-making is high (52\%), however it is not significant ( $p>0.05)$. It is concluded that minor time wasters exist in the STC.
\end{abstract}

Key words: time wasters, decision-making, hesitancy, resort to committees

\section{Introduction}

Since ancient times to the modern era the idea of time and its definition eludes and evolves depending on the diversity and changeability of fields. Time has long been studied and defined by many philosophers and scientists in different fields, but finding a definition that suits all fields seems to be difficult. Two different opinions on time divide many philosophers and scientists. One is the realist opinion which says that time is an independent dimension in the universe wherein events occur sequentially. Isaac Newton shares this opinion, hence it is sometimes referred to as Newtonian time[1; 2] Another opinion disagrees with Newtonian time theory, where time does not refer to any kind of "container" that events and objects "move through", nor to any entity that "flows", but that it is instead part of a fundamental intellectual structure (together with space and number) within which humans sequence and compare events. This opinion led some philosophers to say that time is neither an event nor a thing, thus it can't be measured nor can it be travelled [3; 4].Time is one of the seven fundamental physical quantities in the International System of Units and is used to define other quantities, thus defining time in terms of such quantities would result in circularity of definition. Aristotle (384-332 BC) described the time as a census of movement. Time is a dimension in which events can be ordered from the past through the present into the future,[5;6] and also the measure of durations of events and the intervals between them [7]. Nevertheless, diverse fields all over the world use some of time concepts in their respective measuring systems [8].The simplest and relatively uncontroversial definition of time is that time is what clocks measure[3] and we use it to determine the extent of the events in the past, present and future.

These trials to give a suitable definition for time confirm the special evolving relation between the human being and time that the God wishes. A close relation that: his birth, his death and all the events in his life are linked to and measured with time. The human been guided by the periodic movements of the sun and moon he works in the daytime rests at night and notices and fears natural disasters. Thus daylight is activity and night is stillness. This relation evolved steady and quickly his knowledge of the time increased, he knew the years, months, days, hours, seconds and recently he news the importance of the nano fractions of time. His cognizance of the value of time increased and he realized that if time is lost it can't be recovered again.In the era of communication and technology, the description of time for individuals who are interested to invest their lives, time is a real value for life investment. Hence, wasting time is considered suicide as long as we know that "time is life" this does not mean to refrain from entertainments and recreations. Because the best time management, for future investment, can't be insulated from the laws of the universe and life. The prayers, for example, can be considered an important part in the planning of time and investment, but there are other things that must be disclosed to learn the causes of time wasters and work to avoid them as much as possible, to achieve better results in less time. Time is the life and the most fascinating words that describe this are given by the Egyptian poet Shawki who said: (One's heart beats, say to him life is minutes and seconds).

Thus the main aims of this study are to highlight some definitions of time wasters, determine time wasters related to decision-making in the STC and study the real situation of time wasters related to decisionmaking in the private companies in Saudi Arabia. 


\section{The importance of time for companies}

A triangular multilateral relationship that links between the human, machine and time developed in the modern world. This relationship shows the importance of time as an important component of the universe. Despite the newness of this subject in the literature of modern management; the roots in general are due to the work and efforts of Frederick Taylor the finder of the modern scientific management [9]. Taylor conducted study on how to increase the factory production. In his study he correlated the time to the activities of the labour when conducting certain job. He concluded that there is a large proportion of waste in time, material and human efforts as a result of in adequate regulation and supervision, and that the only way to avoid this loss is the application of new performance methods within the plant to reduce the cost and maximize the production. This means increasing the profits and consequently the wages of workers and employees, leading to prosperity and stability of all. Thus the study of Taylor highlighted the importance of time for production increment, prosperity and stability. The time, in companies and organizations in Arab world, does not appear as a key in the operating records, because it is taken for granted, and then the attitudes and practices of time management are lenient and not serious. Time can't be considered as regulatory tool only, but it also means an essential tool to compete in the market. Thus, Time-Based Management, Time Cycle Reduction, and the Value-Added Time, are fundamental features of strategic competitiveness [10].

\section{The concept of time management}

The focus on the topic of time management in its currently recognized comprehensive sense began in the late fifties and early sixties of the twentieth century. The first attempt in this area is of James MacCay [11] who wrote a book entitled (The Management of Time). The important phrase in this book; which is still in use to date:"If you feel that the time is inadequate in business, it is a sign that your administrative skills are moving towards nothingness". The concept of time management varies among individuals depending on their motivations, needs, the nature of their jobs, and also from culture to culture. There are several definitions of time management starting from the definition of Frederick Taylor [9], but they generally focus on the completion of the work in a coordinated, orderly, effective way to achieve the goals withbestmeansandlowercosts. Thisrequiresagoodandeffectiveexploitationofallpotentialsandresources.

Administration of time means: "The optimal and effective use of the available resources, including time [12].Also time management is known as" The process whereby the time is distributed effectively between the different tasks, in order to complete them in a defined specific time. Alserafi [13] said that "managing time is the process of planning, organizing, directing and controlling the time to enable us to choose the right thing to do and do many things in a short time". Reminding that class of people, who usually says: " There is no more hours in the day and I do not have enough time" there are two important facts: the first there are 24 hours a day, 168 hours per week and 8766 hours per year and the second fact we have equal time, whether we are rich or poor, strong or weak. The meaning and perception of time differ among people and varies with individual affiliation, living in a traditional, developing or sophisticated industrial society. The president of USA has the same amount of time as an employee of small telecommunication company, housewife or are tired man. There is a clear correlation between the extent of underdevelopment of countries and the loss rate of the time caused by their citizens or their misuse of this important resource [14].

\section{Definition of time wasters}

It seems at first glance the definition of time wasters is easy. Phone calls, paperwork, copying machine crashes and social speech, etc. are obvious time wasters. But if a serious effort is done to clarify this definition difficulties clearly appear [12]. What is a time waster for you is also the same for others, and what was a loss of time in the last month, now has become a good recruitment of time, and vice versa. Thus the concept of time wasters is a dynamic that changes with climate conditions, crises, places and people, an activity that takes unnecessary or uses inappropriate time, or an activity that does not give a return commensurate with the time spent on it. Time wasting factors are those factors that prevent the implementation of high value critical businesses. Also they can be defined as businesses that consume a lot of time that not commensurate with the value resulting from their implementation, a limited contribution to achieve the ultimate goal [14]. Then many of those who love life are lost, they do not have a goal, identity or tasks that they would like to do. Ernest Holmes [15] said" My thoughts control my experiences, I can direct my thoughts ". The use of the time depends on the following factors: Who are you? What are you doing? How to deal with your business? What you are trying to accomplish? In order to succeed we must first believe that we can succeed. Napoleon Hill [16] said: "What the human mind perceives and believes can be achieved". We should expect that an individual who insists to perform his work $100 \%$, either he does not have enough work, or he does not fit to work in these days [17].The completion of several works well is better than the completion of one work ideally, unless there is a need to do so[18]. In life there are many factors that intervene to cause wasting of time for administrators and heads and limit the possibility of benefiting from the working time available, we may find that some of these 
factors come from the external environment surrounding the company or associate with customs and traditions, values and patterns of human behaviour prevalent in the community, while others can be found in the internal working environment of the company [13].

Thus it is very important to study time management to learn how to achieve optimal utilization of time. We do not mean to change, amend or develop it, which is not possible. When we are talking about optimum time utilization, we are in fact talking about the utilization of human, financial and administrative resources within this time. Perhaps if we are not able to manage time, we cannot manage anything else. The"Time Management" is a misleading term, because time cannot be managed, but we can only manage ourselves with time. Some of time wasters that affect decision making are summarized in Fig. 1.

Time wasters

Fig. 1. Time waster's analysis model.

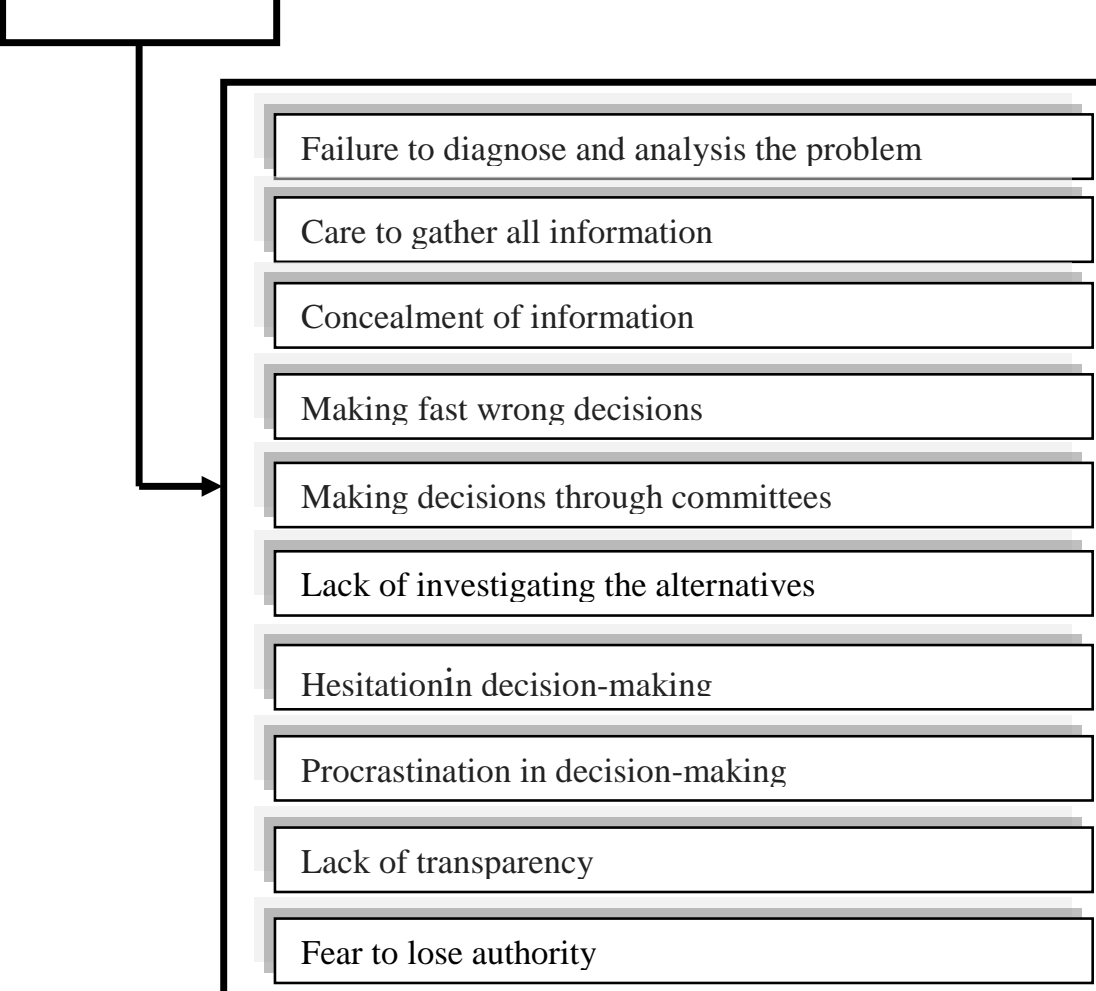

Making poor and weak decisions

VI. The importance of the study

The importance of this study stems from, the scarcity of studies that have been done on time wasters related to the elements of the administrative process, the extent of the needs of private and public companies to spread the culture of time management, self-management and management by objectives, and the need to avoid time wasters so that companies can face changes and competition in the domestic and external environment in the light of the prevailing economic changes. In addition it provides valuable information for researchers and decision-makers in public and private companies.

\section{Problem of the study}

This study addresses the problem of time wasters related to decision-making (extra care to gather all the information when making decisions, to make hasty decisions, decisions by the committees, hesitance in decision-making, to postpone the decision-making) in private companies, taking STC as a model for the rest of private companies especially telecommunication companies. The problem of time wasters casts a shadow on the practice of management in private companies which result in waste of materials and human efforts leading to the failure to achieve companies' objectives. The lack of rational decision-making and the presence of pressure of work leads to a decline in production rates, increases production costs and deteriorates the quality. Thus the company will be weak to compete with local and international companies. 


\section{Study hypotheses}

Time wasters in private companies (caution to gather all the information when making decisions, to make hasty decisions, decisions by the committees, the hesitance in decision-making, postponing the decisionmaking) negatively influence decision-making.

\section{Previous studies}

Salih [19] conducted study to highlight and identify the importance of time. The research problem was how to manage, plan and distributed time to complete the work. This study highlighted the importance of time arrangement in planning and decision-making. The study recommended the need for proper planning of time to increase its effectiveness. Abdul Rahman [20] studied the causes of low productivity and a low level of performance in productive enterprises in Sudan. He summarized the basic aspects of time management for the organization and the individual in need of planning, setting goals, knowing the factors that lead to loss of time and eliminate or control them, and act in accordance with the priorities and programming time for the tasks and activities. The study concluded that workers have consciousness and full aware of the value and importance of time due to the presence of foreign management in the company. Wadaat Allah [21] conducted study on how to invest and utilize working hours to achieve the goals of industrial companies. The most important finding of this study is that the company focused on attendance time and neglected training of personnel therefore; the goals were not achieved despite the concentration on time of attendance. Alsarayra [22] studied the relationship between the performance of the administrative processes and efficiently of time manage at Mutah University in Jordan, and the most important results he found is that the workers realize the importance of time. Alzugbi [23] conducted study on the factors influencing time management in the Jordanian private companies. The study concluded that time wasters collectively impair decision-making. Makkawi[24] studied the ways of time management at the office of taxes that lead to a significant waste in working time. He found that human factors (exchange of visits at work sites, phone calls, TV watching, reading the newspapers and performing of social duties) all are practiced during working time, which lead to time wasting. Ibrahim[25]conducted study on the value of the time as an important factor to achieve the goals of the institution and to identify time wasters and their solutions. The most important finding of the study is that there is a widespread of habits among employees (idleness at work, absence from work, phone calls and visits) that lead to wasting time and must be disposed of. Mahdi (2007) investigated the social and economic factors that lead to waste of time in the public sector in Sudan. He found that the social relations lead to waste of time in the public sector in Sudan.

\section{Methodology}

The study was carried out in Najran city south of Saudi Arabia in the period 2012- 2013. The population of the study was the workers of the STC as a model for the rest of the telecommunications companies. Three levels of employees (department managers, sections managers, operational supervisors) were surveyed with a survey instrument (questionnaire).The survey instrument contained two parts: Section I: focused on personal data of the study sample (gender, age, marital status, educational qualification, specialty, years of experience, career level).Section II: contains 9questions to be answered according to the Likert five scale, which includes five levels (strongly agree, agree, agree to a certain extent, I do not agree, do not agree at all). The questionnaire has been evaluated by 8 specialists in the field of management and the Arabic language, to make sure of the virtual honesty, clarity and wording. The questionnaire's paragraphs stability was tested according to the methods of Cranach's Alpha. An exploratory sample of 10 members of the study population was employed and the consistency was found $79 \%$. The questionnaire was distributed to 75 subjects of the study sample and 50 questionnaires were recovered (recovery rate of 66.6\%). The data were evacuated into tables especially prepared for this purpose.The data were analyzed with Chi- $\times 2$.Probabilities of $P<0.05$ were considered significant.

\section{Study sample characteristics}

As shown in table (1) all the respondents (100\%) were males, 38\% were about 36-40 years of age, 34\% were about $41-50$ years of age, $24 \%$ were about 30 - 35 years, $2 \%$ were about 50 years. Ninety percent are married, $8 \%$ are single and $2 \%$ are widowed. The majority of the study sample holds a bachelor (54\%), $24 \%$ hold intermediate diploma, $12 \%$ holds high diploma, $6 \%$ holds a secondary certificate and $2 \%$ holds a master degree. No Ph.D. or other qualifications (such as professional fellowship) are available. The specialties of respondents surveyed are business administration (22\%), public administration (12\%), accounting (12\%), economic (10\%), computer (4 \%), engineering 2\%, banking $2 \%$ and the remaining(36\%)are from various disciplines. The experience of most of the respondents(94\%) is more than 10years; 5-10 years (4\%) and those with the least experience ( 5 years) are2\%.The supervisors represent the major career (48\%), followed by unit 
managers (40\%), department directors (2\%)and others(technicians 16\%).According to the administrative structure of the company the ratio between supervisors and unit managers is normal.

\section{Results}

As shown in table (2), when the answers of the assumption questions were summed-up high percent of the subjects hesitate and resort to committees when making decisions. The majority of the subjects (72\%), when they want to make any decision, want to reach a rational decision. Most of the subjects (76\%) do not encourage or request information that has nothing to do with the needs of their work. Seventy eight percent of the subjects do not take hasty and wrong decisions. Sixty two percent of the subjects resort to the formation o committees to make decisions. Fifty two percent of the subjects hesitate in making decisions. Those who postpone issues and difficult tasks amount to $30 \%$.Forty percent suffers from delaying and lack of decisiveness. Eighty eight percent of the subjects, when others ask them their time if it opposes the completion of their main tasks, they say no. Ninety six percent of the surveyed sample would say no (without embarrassment) when they are asked to do someone else's work, if it opposes the completion of their tasks.

\section{Discussion}

This study revealed minor time wasters related to decision-making in the STC. This is due to the fact that most of the company's employees are qualified bachelor holders with high cumulative experiences. Diversity of disciplines are clear in the company's structure which shows that the company keep up with and continue to develop its structure and the dominant feature of the company's structure is the engineering and administrative disciplines. The career progression of the company's staff from supervisors, followed by directors of departments and general managers, is normal and consistent with international companies' structure and this is required at the current stage. These factors helped the company to have its own organizational culture that time keeping is a fundamental base of it. Also the study reflects the awareness of importance of time among the company's employees. This study is in consistence with what reported elsewhere [20;22].

This company is suffering from the formation of committees to take decisions. Resorting to committees to make decisions, making committees on a decision that does not need a committee, a committee to approve and decide on a prior decision, making more than one committee to do the same job, assigning a committee to make a decision which is not in its own specialization, or choosing an employee to take part in more than one committee are known as time wasters when making any decision [23].

High percent of the company's employees suffer from hesitancy in decision-making. This is one of the dangerous kinds of time thefts. Many of managers when they arrive at the critical point to make a decision, they hesitate and procrastinate, or in other words, refuse to make a decision. This does not mean lack of decisionmaking, in the appropriate time, is just a time waste; however it entails a lot of concern and problems. The need for more information is the traditional excuse for the delay in the decision-making for those who insist on getting all the information to make the decision. Because the wait to get all the information represents a kind of tampering, absurdity and flaccidity of analysis practices. Risks are present in all the decisions, and there are no decisions without risk, and it is impossible to provide any manger with all information and a decision must be taken with what available. Hesitation in decision-making and lack of motivation to take decision, as well as the feeling that the decision is at rap that subjects its maker to legal liability are common time wasters. The same conclusion was given by Alzougbi [23]. However, Alsarayrah [22] disagreed with it.

On the other hand the study revealed the absence of young employees. This means that there is a defect in the staffing process. Additionally, the lack of doctoral and other qualifications (such as professional fellowship), the increased number of employees with intermediate diploma, and employees with accumulated experience are among the phenomena that reflect the aging of the company, which will affect the company's business future.

\section{Conclusions and Recommendations}

It is concluded that there are minor time wasters related to decision-making in the STC. Furthermore, there is a defect in staffing and lack of young staff. Thus the following recommendations are given:

1. There is a need to consolidate the awareness of the value of time, because it is a very important resource in economic and social development. It is essential to use time planning, management (such as management by objectives, energy management, self-management, tables and waiting lines) and programming the time of the company's employees and drawing their attention to work.

2. There is a need to develop training programs in time management for company's employees to achieve the goals of the company.

3. In the staffing process the company must adhered to the job description taking into account the application of the principle of justice. 
4. The company must develop programs to rehabilitate and train the personnel and adopt a positive approach to comprehensive planning.

5. The company must raises the skills of the staff and increases their awareness of some of the concepts of management and how to make decisions, whether personal, regulatory, collective, routine, planned versus emergency or even major decisions ... etc..

6. The company must raise the skill of the staff to manage committees, set clear goals for each committee and determine the duration of the committees and abide to them.

7. When the company's management adopt any policy or any action regarding the need to respect the work of the company, it must be clear to everyone working in the different administrative levels.

8. The company must work to legalize the procedures and regulations adopted to achieve the goals, and to develop fixed known standards for to the daily performance of the workers.

9. Each company or unit must follow he scientific method in developing an action plan to achieve the desired goals, according to specific priorities.

\section{References}

[1]. R. Robert. Newton's view on space, time and motion. Stanford Encyclopaedia of Philosophy. . Stanford University. Winter 2004

[2]. M. Ned. Time. In Edward N. Zalta. The Stanford Encyclopaedia of Philosophy. Winter 2002.

[3]. B. Douglas (2006). Gottfried Wilhelm Leibniz (1646-1716) Metaphysics - 7. Space, Time, and Indiscernible. The Internet Encyclopaedia of Philosophy, 2006.

[4]. M. Matt. Immanuel Kant (1724-1804) Metaphysics: 4. Kant's Transcendental Idealism. The Internet Encyclopaedia of Philosophy, 2006

[5]. D. Paul. About Time: Einstein's Unfinished Revolution. Simon \& Schuster, 1996.

[6]. Oxford Dictionary. Time. Oxford University Press, 2011.

[7]. L. Robin (2004). The Experience and Perception of Time. In Edward N. Zalta. The Stanford Encyclopaedia of Philosophy, 2004.

[8]. Z. Kenneth. Getting organized at work: 24 lessons to set goals, establish priorities, and manage your time. McGraw-Hill, 2008.

[9]. F. W. Taylor. The Principles of Scientific Management. Harper and Brothers, New York, 1911.

[10]. R. M. Alian. Time management theory and practice. Dar Greer publication, $1^{\text {st }}$ ed. Amman, 2005. (In Arabic).

[11]. J. T. McCay. The Management of Time. New York: Prentice-Hall, 1989.

[12]. Abu Sheikha, N. A. Time management. Dar Majdalawi, ${ }^{2 n d}$ ed., Amman, 2002. (In Arabic).

[13]. Alsirefi, M. Time management. Horus Foundation for publication and distribution, $1^{\text {st }}$ ed., Alexandria, 2006.(In Arabic).

[14]. A. F. Diab. The art of managing time and meetings. Publishing House of the Universities, $1^{\text {st }}$ ed. Cairo, 1999. (In Arabic).

[15]. E. Holmes. The science of mind. Tarcher Putnam, 1926.

[16]. N. Hill. Napoleon Hill's Keys to Success: The 17 Principles of Personal Achievement. Dutton Books, 1994

[17]. A. A. Alkhuzami. Time Management - Managing Life. Ibn Sina Library for Publishing and Distribution and Export, $1^{\text {st }}$ ed., Cairo, 1999. (In Arabic).

[18]. S. Mahmoud. Time is life: How to manage your time. Dar Alnashr Alislamya, $1^{\text {st }}$ ed., Cairo, 1996. (In Arabic).

[19]. I. Salih. Time and its impact on the planning, Study of the effectiveness of the administrative decision. MSc. thesis. Omdurman Islamic University, Khartoum, Sudan, 1999. In Arabic

[20]. N. A. Abdul Rahman. Time management in the production sector - a case study of Kenana Sugar Company Limited 19801999.MSc. thesis. Sudan University of Science and Technology, Khartoum, Sudan, 2000. In Arabic

[21]. M. O. Wadaat Allah. Time wasting and its impact on productivity in the private and public sectors in the state of Khartoum from 1996 to 2001.PhD. Thesis, Sudan University of Science and Technology, Khartoum, 2002. In Arabic

[22]. E. A. Alsarairah..The relationship between the performance of management processes and enough time management and its effectiveness - a field study of the administrative units in Mutah University - Jordan from $1999 \mathrm{~m}$ to 2002. MSc. thesis, Sudan University of Science and Technology, Khartoum, Sudan, 2000. In Arabic.

[23]. A. F. M. Alzougbi. The factors affecting the management of time by production managers in the Jordanian private sector companies in 2001 - Analytical Field Study: MSc, thesis, Sudan University of Science and Technology, Khartoum, 2002.In Arabic.

[24]. S. S. Makkawi. Time management: a case study of Khartoum tax office in the period of 2001-2002.MSc, Khartoum University, Sudan, 2003. (In Arabic).

[25]. M. Y. M. Ibrahim. Time management in the services sector an empirical study Umbadadh Locality, Khartoum 1995 to 2003.MSc, thesis, University of Juba, Khartoum, Sudan, 2004. (In Arabic).

[26]. S. A. Mahdi. Social and economic motives for wasting time in the public sector in Sudan. Ph.D. thesis, Khartoum: University of Juba, 2007. (In Arabic). 
Table (1). Characteristics of the surveyed sample

\begin{tabular}{|c|c|c|c|}
\hline Serial no. & Gender & No. & $\%$ \\
\hline 1 & Male & 50 & 100 \\
\hline 2 & Female & 0 & 0 \\
\hline \multicolumn{2}{|r|}{ Total } & 50 & 100 \\
\hline Serial no. & Age in years & No. & $\%$ \\
\hline 1 & $<30$ & 0 & 0 \\
\hline 2 & $31-35$ & 12 & 24 \\
\hline 3 & $36-40$ & 19 & 38 \\
\hline 5 & $>50$ & 2 & 4 \\
\hline \multicolumn{2}{|r|}{ Total } & $\mathbf{5 0}$ & 100 \\
\hline Serial no. & Marital status & No. & $\%$ \\
\hline 1 & Married & 45 & 90 \\
\hline 2 & Single & 4 & 8 \\
\hline 3 & Widowed & 1 & 2 \\
\hline \multicolumn{2}{|r|}{ Total } & 50 & 100 \\
\hline Serial no. & Qualification & No. & $\%$ \\
\hline 1 & High school & 3 & 6 \\
\hline 2 & Intermediate Diploma & 13 & 26 \\
\hline 3 & Bachelor & 27 & 54 \\
\hline 4 & High Diploma & 6 & 12 \\
\hline 5 & Master & 1 & 2 \\
\hline \multicolumn{2}{|r|}{ Total } & 50 & 100 \\
\hline
\end{tabular}

\begin{tabular}{|c|c|c|c|}
\hline Serial no. & Specialty & No. & $\%$ \\
\hline 1 & Management & 11 & 22 \\
\hline 2 & $\begin{array}{c}\text { General } \\
\text { management }\end{array}$ & 6 & 12 \\
\hline 3 & Accounting & 6 & 12 \\
\hline 4 & Economics & 5 & 10 \\
\hline 5 & Engineering & 1 & 2 \\
\hline 6 & Accounting & 2 & 4 \\
\hline 7 & Banking & 1 & 2 \\
\hline 9 & Others & 18 & 36 \\
\hline \multicolumn{2}{|c|}{ Total } & 50 & 100 \\
\hline Serial no. & Experience & No. & $\%$ \\
\hline 1 & $<5$ years & 1 & 2 \\
\hline 2 & $6-10$ years & 2 & 4 \\
\hline 3 & $>10$ years & 47 & 94 \\
\hline \multicolumn{2}{|c|}{ Total } & 50 & 100 \\
\hline Serial no. & Career & No. & $\%$ \\
\hline 1 & Dep. Manager & 1 & 2 \\
\hline 2 & Unit Manager & 20 & 40 \\
\hline 3 & Supervisor & 24 & 48 \\
\hline 4 & Others & 5 & 10 \\
\hline \multicolumn{2}{|c|}{ Total } & 50 & 100 \\
\hline
\end{tabular}

Table (2). Assumption questions responses results (number/\%)

\begin{tabular}{|c|c|c|c|c|c|c|c|c|}
\hline $\begin{array}{c}\text { Serial } \\
\text { no. }\end{array}$ & Questions & $\begin{array}{l}\mathrm{No} / \\
\%\end{array}$ & 5 & 4 & 3 & 2 & 1 & Total \\
\hline \multirow{2}{*}{1} & \multirow{2}{*}{$\begin{array}{l}\text { When making any decision I want to reach } \\
\text { a rational decision }\end{array}$} & No. & 6 & 17 & 13 & 10 & 4 & 50 \\
\hline & & $\%$ & 12 & 34 & 26 & 20 & 8 & 100 \\
\hline \multirow{2}{*}{2} & \multirow{2}{*}{$\begin{array}{l}\text { I do not encourage and request information } \\
\text { that has nothing to do with the needs of my } \\
\text { work }\end{array}$} & No. & 2 & 24 & 12 & 11 & 1 & 50 \\
\hline & & $\%$ & 4 & 48 & 24 & 22 & 2 & 100 \\
\hline \multirow{2}{*}{3} & \multirow[t]{2}{*}{ I take hasty and wrong decisions } & No. & 0 & 2 & 9 & 25 & 14 & 50 \\
\hline & & $\%$ & 0 & 4 & 18 & 50 & 28 & 100 \\
\hline \multirow{2}{*}{4} & \multirow{2}{*}{$\begin{array}{l}\text { I resort to committees formation when } \\
\text { making decisions }\end{array}$} & No. & 2 & 13 & 16 & 17 & 2 & 50 \\
\hline & & $\%$ & 4 & 26 & 32 & 34 & 4 & 100 \\
\hline \multirow{2}{*}{5} & \multirow[t]{2}{*}{ I hesitate in making decisions } & No. & 0 & 8 & 18 & 17 & 7 & 50 \\
\hline & & $\%$ & 0 & 16 & 36 & 34 & 14 & 100 \\
\hline \multirow{2}{*}{6} & \multirow[t]{2}{*}{ I postpone issues and difficult tasks } & No. & 1 & 7 & 7 & 18 & 17 & 50 \\
\hline & & $\%$ & 2 & 14 & 14 & 18 & 34 & 100 \\
\hline \multirow{2}{*}{7} & \multirow{2}{*}{$\begin{array}{l}\text { I suffer from delaying and lack of } \\
\text { decisiveness }\end{array}$} & No. & 1 & 3 & 16 & 20 & 10 & 50 \\
\hline & & $\%$ & 2 & 6 & 32 & 40 & 20 & 100 \\
\hline \multirow{2}{*}{8} & \multirow{2}{*}{$\begin{array}{l}\text { I say "no "when others ask my time if it } \\
\text { opposes the completion of the main tasks }\end{array}$} & No. & 6 & 20 & 18 & 5 & 1 & 50 \\
\hline & & $\%$ & 12 & 40 & 36 & 10 & 2 & 100 \\
\hline \multirow[b]{2}{*}{9} & \multirow{2}{*}{$\begin{array}{l}\text { I say no (without embarrassment) when I } \\
\text { am asked to do someone else's work, if it } \\
\text { opposes the completion of my tasks }\end{array}$} & No. & 9 & 19 & 19 & 2 & 1 & 50 \\
\hline & & $\%$ & 18 & 38 & 38 & 4 & 2 & 100 \\
\hline
\end{tabular}

